\title{
ECONOMIC FACTORS INVOLVED IN MAINTENANCE PROVISIONS OF PUBLIC UTILITY CORPORATE MORTGAGES ISSUED IN SERIES
}

The increasing popularity of the open-end mortgage, evidenced by its extensive use in recent utility bond issues, is due to the flexibility in capital structure that it permits, since indefinite additions to the capital structure may be made without reorganization or new financing. The future standing of the bonds to be sold under the open-end policy is, however, dependent upon the wisdom of the financial policy of the issuing company. It is obvious that a public utility company has not the freedom of action that characterizes the manufacturing or other business corporation. By reason of the public interest involved, the utility is obliged to change its business methods on the order of the Public Service Commissions or other regulatory bodies. Many of these changes, such as the replacement of all old equipment with new equipment of more modern design, necessitate that the utility be able to raise large amounts of capital from time to time. Some restriction of the affairs of the company is necessary in order that the purchasers of the bonds may be protected; yet at the same time the corporation must not be so restricted as to hamper its activity.

The subject matter of this article discusses one of these necessary restrictions; namely, how to insure the perpetuation of the property through proper provisions with respect to its maintenance and the provision of adequate renewal and replacement reserves. In many cases of insolvency, the bondholders have found themselves in possession of a property, which, because of insufficient maintenance and renewals, is appraised at less than the bonded indebtedness of the corporation. Insufficient maintenance funds soon result in deterioration of the physical property with inevitable results.

The necessity for elastic and efficient maintenance and renewal provisions in the open-end mortgage is even greater than in the old closed type of mortgage, because of the long span of 
life of the former. The fundamental problem in the formulation of the maintenance provision in the indenture is an economic one and a correct solution of the problem must be based on an analysis of the economic factors involved and a study of past experience as casting light upon future requirements.

\section{Variable Elements W hich Must Be Considered in Formu- lating the Maintenance Provision}

Capital, as employed in public utility enterprises, is undergoing a process of constant change. This is true both of circulating and fixed capital, although the change is more apparent in the case of circulating capital than it is in the case of fixed capital, in which the process of change due to use and other causes is a slower and more subtle one. Fixed capital, taking the form of machinery or any item of physical equipment, is gradually worn out or consumed in the process of production in a manner similar to the consumption of coal or oil, though the consumption of coal or oil is visible and apparent, while the consumption of the fixed capital is not so apparent and extends over a longer period of time. In other words, the activities of production ultimately consume the various forms of capital identified with them, whether this capital is coal or machinery, though in some cases the consumption is immediate, while in others it is spread over periods of varying lengths. ${ }^{1}$

The factors responsible for this loss that takes place in the physical plant and equipment have been enumerated as follows: ${ }^{2}$

"(I) Natural wear and tear.

(a) Invisible deterioration such as a gradual and almost imperceptible weakening of parts, which is above and beyond the maintenance in working order. ${ }^{8}$ (Igro).

${ }^{2}$ Binghamton Light, Heat and Power Co., 2 N. Y. ad Dist. P. S. C. R. I7I

'Sealy, The Accounting Treatment of Depreciation, Procendings of THE Aarerican RaIlway Association (I914).

"It should be emphasized that part of the loss included under "Natural Wear and Tear" is due to mere lapse of time. (Footnote by the author.) 
(2) Accidental breakage or unusual destruction.

Injury or destruction of property by the elements or by an accident in a manner or to an extent not covered by other insurance.

(3) Obsolescence.

The necessity of replacing apparatus because in the progress of the art more efficient apparatus has been invented.

(4) Inadequacy. ${ }^{4}$

The necessity of superseding apparatus bed cause the growth of the community, or the increased demand for the service, necessitates a plant on a larger scale, making the existing equipment inadequate.

(5) Public requirement.

The necessity of superseding apparatus because the public authorities have required construction by a different method or at a different place to meet the public convenience: for example, the superseding of overhead by underground wires or the changing of the location of poles from one street to another."

The destructive work of the several factors above enumerated is always present. Practically all parts of the physical property of the utilities, outside of the land, begin to deteriorate as soon as the plants are ready for operation, and this deterioration continues until the property becomes useless, unless it is overcome by some counteraction on the part of the utilities. The question now arises, in what way or by what method can the extent of the loss in value to plant and equipment, which will be caused by the future operation of the above-described factors, be accurately measured, in order that the company might make adequate provision to offset this loss? Thus, for example, is there any human medium at hand for predicting with any degree of accuracy the

"Inadequacy should not be confused with "Additions to Plant." A line of demarkation must be drawn between loss due to inadequacy included under "Maintenance," and loss due to inadequacy included under "Additions to Plant." (Footnote by the author.) 
extent or severity of the damage which may be inflicted upon the equipment of utilities in the distant future by storm or other action of the natural elements? Certain acts of God often cause considerable expense to the public utility because a great percentage of its equipment is exposed to the weather. For instance, the overhead wire systems of electric utilities are subject to intense wear and tear during a severe electrical storm, snowfall or sleet storm. In addition the rolling stock of an electric railway is also subject to damage by unfavorable weather conditions, and the direct effect that the weather might have upon the number and severity of collisions is of some importance in determining the extent of the future loss in value that will take place in the equipment of street car lines.

It is evident that insurance can be utilized as a means for partially offsetting future losses caused by certain "acts of God." However there exists in the hazards of the future the possibility of vicissitudes and catastrophes which are not insurable. Such losses, in accounting parlance, are most often termed "unusual destruction."

It is also correspondingly difficult and in most cases impossible to predict accurately the rate at which future obsolescence will operate on plant and equipment. The shortening of the life of physical property, as a result of changes in the art, is a matter of almost daily occurrence with the various types of public utilities. In the past, inventions have made obsolete equipment which theoretically had a useful future life of many years. There are absolutely no criteria ${ }^{5}$ present by which the rate of this future

${ }^{5}$ In the Report of the Gas Commission to the Mayor and Council of the City of Philadelphia, May, r92r, the Commission pointed out the economies resulting from the substitution of the more modern vertical retort equipment in place of the horizontal retort equipment, and the fact that the use of by-product coke ovens is developing rapidly-(pp. 58-6r, Report). The following is a quotation from page 67 of the report:

"The Commission cannot overemphasize the crucial character of the present situation. The gas industry is passing through a serious phase of its development. The high price of gas-making materials, particularly gas oil, has upset all predictions and expectations. Some solution must be found, for the gas industry can not pay Io cents to 14 cents for oil, and high prices for gas coal, unless some method is found for increasing the yield per unit of raw material used or by some other means reducing the holder cost."

In the case of interurban and street railway lines there exists at the present time the economies of direct current railway operation as contrasted with alter- 
development in the art can accurately be measured. In fact, opinions of experts have been contradictory. Some think that we are entering upon a period of slow development, while others think that we are entering upon a period of most rapid development. If the latter opinion proves to be correct, a much larger reserve allowance to provide for the development is necessary than if it turns out that the former opinion is accurate.

The extent of the development of the community or the rate of increase in the demand for additional service which will take place even a few years hence cannot ordinarily be measured, and therefore it may be impossible to know with any degree of accuracy the extent of the loss in value which will occur in the plant and equipment due to "inadequacy." For example, an unpredictable growth of a city might lead to the supersession of the physical property of a utility before the property had arrived at the end of its physical life, if the original units of plant and equipment are incapable of fulfilling the increased demands made upon them, and it is also possible that a sudden decline in the population of a community or in the popular demand for the service rendered by the utility would cause a loss in the value of some units included in the plant and equipment. This loss must properly be charged off to inadequacy.

It is likewise impossible to predict accurately the requirements which will be forced upon the utilities by the future actions of the public authorities, and indeed unforeseen elements might even affect the extent of the work of the factor "wear and tear." For example the phenomenal growth in the number of trucks and automobiles used has lessened the life of the tracks of street car lines.

The radical revolution in paving requirements incident to the widespread use of pleasure and business automobiles has

nating current. These economies are due to the great improvement in direct current operation such as the development of the interpole and seif-ventilated motor, the amplification of control apparatus and the satisfactory development of the automatic rotary converter substation. For example, the Indianapolis and Cincinnati Traction Company changed over their system in the Spring of I923, not because their alternating current system was worn out, but because the newer system of direct current operation was more efficient. (See Electric Railway Journal, June 2, I923, 913.) 
shortened both the physical life and useful life of street paving. The destructive effect of heavy trucks upon the older types of paving has been so tremendous as to require the practical reconstruction of all main highways. The change in the type of paving thus required has forced the municipality to repave streets much sooner than was estimated to be necessary by competent engineers at the time the paving was laid. The destructive effect of automobiles while the paving was in existence has increased the maintenance expense of electric railways, which in most cases are required to keep the tracks between the rails and for a certain distance outside thereof in good repair.

The reconstruction of the paving introduced a serious problem to the electric railway. The track reconstruction work of the average city electric railway must be largely regulated by the paving program of the municipality. It is cheaper in most cases for an electric railway to discount the remaining useful life of its track and renew the track at the time the city replaces the pavement, sacrificing the remaining useful life of the track, than to bear the expense of both tearing up and repaving the street which would be required if the railway company waited until the full wearing value of the track has been exhausted. It is the almost universal experience of all electric railway properties that the rate at which track must be reconstructed has been greatly accelerated as the result of the revolution in paving requirements which has followed the general introduction of automobiles.

Another problem, which must be taken into consideration in determining the future extent of the loss in value of plant and equipment due to "wear and tear," arises from the fact that the length of service of equipment, or the "useful life of equipment," is often variable for equipment of the same type, even though located in the same vicinity, and given the same amount of work to perform. This, of course, is due to the effects of the varying natural forces encountered. ${ }^{6}$ This variability is emphasized when

\footnotetext{
- "The annual depreciation allowance for a gas plant should be sufficient to replace the main parts of the property when the same have deteriorated from causes other than operation, such as the mineral character of the soil in which mains are laid, and the character of the water used in the boilers." El Reno $\mathrm{v}$. EI Reno Gas \& Electric Company, P. U. R. I9I5A 226 (Okla.).
} 
comparisons are made of similar equipment located in different sections of the country. A Committee of six members, known as the joint committee on life of railway physical property, was appointed in I9I9, by the American Electric Railway Association through its allied association, i. e., American Electric Railway Engineering Association and American Electric Railway Accountants Assocation, to investigate the subject of depreciation. After three years of study of the life of railway physical property, from every source obtainable, including the accumulation of a complete bibliography of the subject, this joint committee concluded that it is not practical or even theoretically possible compositely to assemble the several basic elements which determine the life of railway physical property into any form of a logical "life table" that will apply equally in Maine and in California, in Minnesota and in Louisiana, or on different routes or lines of the same system embracing such physical property. F. W. Doolittle emphasizes this when he refers to the different experiences of corporations in maintaining their equipment, when they were using the identical type of equipment. ${ }^{\top}$

Taking into consideration the fact that the future extent of the damage caused by the operation of the various elements mentioned cannot be accurately predetermined, the difficulty of the problem of accurately fixing the annual appropriation which should be made by the utility in order to overcome the future effect of each and every one of these elements is obvious. ${ }^{8}$

The practice of utilities, as a rule, is to set aside out of income certain amounts in order to provide for current require-

This diversity of experience is evident from the studies of the life of physical property which have been made by the American Electric Railway Association and similar associations abroad. There have appeared in various textbooks from time to time, tables of hypothetical lives of physical property, the accuracy of which in the light of these investigations may be seriously questioned.-F. W. Doolitite, Studies in the Cost of URBan TRansportation SERVICE (published by the American Electric Railway Association, 1916) 63.

8 "Accrued depreciation of utility property is something to be completely determined by inspection rather than by a theoretical yardstick." Winona v. Wisconsin-Minnesota Light \& Power Co., P. U. R. I922C 461 (D. C. Minn.).

"The amount to be allowed annually for accruing depreciation of an electric plant is partly a matter of judgment, and something of averages, not susceptible of exact ascertainment." Ketterlinus v. Bar Harbor U. R. Power Co., P. U. R. I920B 513 (Me.). 
ments and to create a reserve which can be used to offset future losses occasioned by the operation of the several mentioned factors. Although universally called a "reserve" it is not really such. The usual practice of the ultility is to take from its earnings each year the sum fixed for such reserve and place it in new equipment and additions to plant. Instead of having a cash fund available to meet such expenditures, new equipment is constantly purchased for replacement of that equipment whose "useful life" is coming to an end and for independent additions to plant, such expenditures being credited, for bookkeeping purposes, to the reserve fund. In this way the efficiency is maintained at one hundred per cent. and the capital structure is unimpaired. This amount may be treated as a single reserve or it may be divided among two or more reserves, depending upon the accounting practice of the particular corporation. In the latter case, these reserves are usually referred to as maintenance, depreciation and renewal reserves, the terminology depending as a rule upon the number of accounts which the corporation sets up. The specific purposes of the several reserves may be clarified by the consideration of definitions which were formulated by a committee on valuation representing the American Electric Railway Association. The definitions read as follows:

"Maintenance-The cost of repairs and renewals for proper upkeep of property. Maintenance is of two kinds:

(a) Ordinary maintenance. Those repairs which are made when needed.

(b) Deferred maintenance. Those repairs which cannot economically be made each year, but which are made at frequent intervals.

"Depreciation-Is the lessening in worth of physical property to use or other causes.

"Obsolescence-The state of becoming obsolete (Webster). The replacement of property before it has reached its full period of usefulness due to

(a) The advance of or changes in the art or process in practice, or

(b) Public legislation or demand." 
Thus the maintenance reserve presumably covers the costs of maintenance; the depreciation reserve presumably offsets the loss occasioned by depreciation; and obsolescence is to be taken care of by a renewal reserve. Theoretically, then, a property requires that a certain amount be expended for depreciation and obsolescence, as well as for making the so-called necessary repairs. In practice, however, it is extremely difficult and most often impossible accurately to differentiate between that part of the destruction which should properly be cared for under maintenance, and that which should be under depreciation. ${ }^{9}$

It would be a hazardous task to prove that the effect of obsolescence is different from the effect of depreciation. When a machine becomes obsolete, it cannot function efficiently, and it might indeed then be cheaper to scrap it and to replace it with more modern equipment. Likewise when a machine depreciates it cannot function as efficiently as before depreciation set in, and the time arrives when it is necessary to replace it. To add to the difficulty of allocating the destruction of the plant and equipment to these several captions is the fact that all three factors are operating simultaneously on the same equipment. At the same time the unit was depreciating, obsolescence was setting in and in addition it required a certain amount of repair. When the questions arise where does obsolescence set in, and where does depreciation cease, and again how much of the wear and tear shall be charged to maintenance, the answer is that in most cases it is an impossible task to determine accurately where these individual factors commence and cease to operate. Thus if plant and equipment are maintained to the extent of the greatest possible effciency, it follows that no depreciation or obsolescence is present. It appears that the problem is sufficiently difficult without attempting to segregate under various captions the loss in value of plant

\footnotetext{
- As an Indiana Court put it, "There is no precise and accurate differentiation of maintenance from depreciation. But between these two extremes, there is a twilight zone in which it is very difficult and not very important to determine whether the expenses should be charged to maintenance or depreciation. One fact, however, ought not to escape observation. The larger the maintenance fund that is maintained, the smaller the depreciation fund that shall be maintained. Each is in a measure maintenance, and each is in a way replacement." Peck v. Indianapolis $L$. and H. Co., P. U. R. IgI6B 445,484 (Ind.).
} 
and equipment which takes place due to time and use. The imperative duty is for the company to recognize the presence of this loss to its plant and equipment, and then attempt to set aside periodically an adequate sum the use of which will enable them to maintain the property on an approximately one hundred per cent. efficiency basis. Thus the sum must be sufficient to provide for the current requirements for maintenance and renewals, and in addition, to provide whatever amount may be necessary for the purpose of having available, as required, a sufficient amount to enable the company to make replacements when the units reach the end of their physical life or when they must be retired because of changes in the art or due to inadequacy. The economic problem, therefore, is one of determining a method by which the utility can be required to set aside a sufficient sum out of its earnings each year to provide for adequate maintenance ${ }^{10}$ and renewals. The investor is entitled to demand that a sufficient sum be set aside and expended to preserve not only the physical integrity of the investment but its full service value so that the property is able to properly function at all times. It might be argued that his selfish interest would be best served by requiring the company to set up more than might be adequate. 'On the other hand, we must remember that the operating expenses of a utility, particularly the amounts which should be expended or set aside for renewals and replacements, may be subject to the regulation of a public service commission which, on complaint, has the power to see that not more than a sufficient sum is collected from rate payers for the purpose of preserving the integrity of the property. A mortgage requirement which was manifestly unreasonable would be set aside by a state commission just as would be the case if the mortgage requirement was less than the commission in its judgment believed sufficient. Commission regulation, however, has not reached the point where the commission has original jurisdiction to make adequate provision for renew-

\footnotetext{
${ }^{10}$ Adequate Maintenance implies maintaining the plant and equipment in the highest possible state of operating efficiency.
} 
als and replacements. Unless and until the jurisdiction of the regulatory bodies is thus expanded, the utility must attempt to secure the desired end by provisions in the corporate mortgage.

The illustrations given above indicate the difficulties of endeavoring to determine the useful life of the property and the rate of renewal which will be required in the future. Another factor even more problematical is presented. In studying this problem it is necessary to keep in mind that the future level of prices will be a most important element in determining the amount of the necessary reserve. If the price level, for instance, in I940 is higher than the level was in 1924 , it will follow that the money costs of maintaining a property in I940 will be correspondingly greater. The opposite situation would exist if there should be a marked recession in the average price levels between 1924 and 1940. The nature of the problem which is presented is well illustrated by the effect of the radical change in price levels which resulted from the World War. The variations in the cost of reproduction of a utility property are roughly typical of the changes in the cost of maintenance and renewal of that property. The following illustration taken from the Valuation Report of the Richmond Railway Division of the Virginia Railway and Power Company is in point. ${ }^{11}$

Cost of Reproduction New of the Property as of January I, 1920, at prices of January $I$, I9I4, prepared by Stone and Webster....\$7,337,314

Cost of Reproduction New of the Property as of January I, I920, at prices of January $I$, I920, prepared by Stone and Webster....\$14,382,410

This indicates that identical type of reproduction would cost approximately 100 per cent. more in 1920 than in I9I4.

A quotation from the report of the Special Commission for the investigation of the Affairs of the Rhode Island Company, written in I9I8, clearly outlines the problem:

${ }^{12}$ Electric Railway Journal, Jan. 27, I923, 161. 
"It is important to note that the annual depreciation allowance, having been calculated from the cost of reproduction reflected in average prices of approximately 1915 , would not be adequate to provide for reneweals on the basis of I9I7 prices, which have increased greatly over those of I9I5; the I9I7 prices reflect war conditions and are therefore abnormal. Nothing can be positively predicted as to where the price level will rest after the conclusion of the war. If prices continue at their present level, it will be necessary for the Company to increase the allowance above the figure we have estimated."

It is interesting to note that in most articles on the subject of depreciation, those arguing for one method or another for computing depreciation appear to take the position that the United States is dealing in a money whose purchasing value remains stationary throughout the passage of time. That our money has fluctuated in purchasing power since the World War is generally recognized, but the fact that it has continually fluctuated in purchasing power is not so generally recognized. The expression is often heard that prices will get back to normal, or again that we must return to "normalcy." The question is immediately raised-what is meant by normal; and when were prices in the United States normal? Were prices normal in 1861 , or in 1896 , or in 1914 , or in 1922 ? The only accurate answer to that question is, the purchasing value of our dollar has been undergoing yearly changes. Consequently no assumption can be made that there ever has been any particular period which can be labelled normal.

It might be well a this time to recapitulate, in order to impress the reader with the gravity of the problem confronting the utility or the investor in attempting to prescribe in advance an adequate standard of maintenance. Every utility must appropriate from its earnings certain sums the amount of which are determined by the operation of the factors known as natural wear and tear, accidental breakage or unusual destruction, obsolescence, inadequacy and public requirement, and by any other factors which may affect the life or efficiency of plant and equipment. In addition any change which may occur in. the general 
level of prices must be considered. The extent of the loss to plant and equipment which will take place during an indefinite period in the future, and the movements of the general price level are variable and not capable of accurate predetermination. Therefore it naturally follows that the investment banker or the utility cannot accurately determine in advance the amount which must be expended adequately to maintain the property during the future expanse of time.

The corporate mortgage, by the use of which the utility expects from time to time to obtain additional capital, usually contains certain maintenance provisions, or covenants, designed to safeguard the integrity of the physical property thus presumably protecting the investment of the bondholders in the property. At the same time, the maintenance provisions should not endanger the future earning power of the company, since a permanent or even temporary diminution of the earning power is as great a loss to the bondholders as if a portion of the physical property itself had been destroyed.

Maintenance must be regarded as an operating expense which should be borne by the customers through the rates paid by them for the service rendered by the utility. In addition equal justice between investors and customers requires that under usual conditions the rates paid by the latter should be high enough to meet all reasonable costs in keeping intact the security behind the investment, thus insuring its ability to render the highest type of service to the public. ${ }^{12}$

${ }^{12}$ The Supreme Court of the United States in the Knoxville case [Knoxville v. Knoxville Water Company, 2I2 U. S. I (1908) ] clearly stated the law and equities of the case and the obligations of both the public and the utility.

“: . the company is entitled to earn a sufficient sum annually to provide, not only for current repairs, but for making good the depreciation and replacing the parts of the property when they come to the end of their life. The company is not bound to see its property gradually waste, without making provision out of earnings for its replacement. It is entitled to see that from earnings the value of the property invested is kept unimpaired, so that, at the end of any given term of years, the original investment remains as it and was at the beginning."

"If, however, a company failed to perform this plain duty and to exact sufficient returns to keep the investment unimpaired, whether this is the result of unwarranted dividends upon overissues of securities, or of omission to exact proper prices for the output, the fault is its own. When, therefore, 
Of course, under such conditions it behooves the utility to make certain that the amounts thus paid by the customers shall be devoted to the purposes for which they were properly intended. It is also the duty of investment bankers and the managers of utilities in drawing up indentures for the purpose of providing capital both now and in the future to make certain that it does not contain covenants and agreements which they believe will be impossible of fulfillment, because of limitations imposed by the rulings of commissions. If conformance with this principle would make it impossible to draw an indenture satisfactory to the investor, it would be far better that the utility refrain from borrowing capital, thus thrusting the burden directly upon the shoulders of the commissions.

The Examination of the General and Specific Type of Maintenance Provistons

The covenants contained in public utility mortgages with respect to the obligation of the company to maintain its property adequately and to make renewals and replacements from time to time are quite dissimilar. This dissimilarity is in part due to the differences in the nature of the several classes of utility business and the specific requirements of each. There has been, moreover, a well defined development in the art of drawing these sections of corporate mortgages.

The earlier public utility mortgages almost without exception contain a general covenant that the company will maintain its property in a high state of efficiency. A typical provision is as follows:

"And said grantor hereby covenants and agrees, that, having possession as aforesaid, . . . it will, at all times, keep and maintain its property in thorough repair, working order and condition, and duly supplied with motive power, generators and equipments, and that it will, from time to

a public regulation of its prices comes under question, the true value of the property then employed for the purpose of earning a return cannot be enhanced by a consideration of the errors in the management which have been committed in the past." 
time, make all needful and proper repairs and replacements, to that the business of the said grantor shall at all times, be properly conducted." 13

The sad experience of bondholders, who found upon the default of interest that the property secured by their mortgage was in an indifferent state of repair, with large expenditures required to remedy deferred maintenance, spurred investment bankers and their attorneys to an attempt to define a standard of maintenance which the company should be required to observe. However, the great majority of public utility mortgages executed prior to the general introduction of the open end mortgage, contained a covenant of the general character above illustrated.

A comparatively few public utility mortgages, issued shortly prior to the introduction of the open end type mortgage, contained covenants requiring the utilities to set aside specific amounts out of gross earnings for the purpose of maintaining and renewing the properties. The following provisions for example, are found in the mortgage given by the Texas Electric Railway Company to the Harris Trust and Savings Bank, Trustee, dated January 1, I9I7:

x. The company will establish a special Trust Fund to provide maintenance.

2. The company will furnish the Trustee with an annual statement showing

(a) aggregate gross earnings;

(b) total maintenance and renewal expenditures;

(c) expenditures for additions and extensions paid for in cash and for which no bonds have been issued;

(d) unexpended cash balances remaining in Trust Fund.

3. The company will deposit in cash in the Trust Fund, the following amounts: the amount by which

Eleven per cent. of the gross earnings for I9I7

Twelve per cent. of the gross earnings for 1918

Thirteen per cent. of the gross earnings for I919

\footnotetext{
${ }^{13}$ Although these provisions varied in details, they all contained fundamentally the same obligation.
} 
Fourteen per cent. of the gross earnings for 1920

Fifteen per cent. of the gross earnings from I92I to 1945 inclusive

exceeds the amount expended under Sections $2(b, c)$.

4. The Trust Fund may not be drawn against by the company unless they have made replacements, renewals, extensions, etc., and deliver to the Trustee a sworn statement that they have done so, and if no bonds have been issued to pay for such replacements, etc.

The problem of designing a proper covenant with respect to maintenance is much more difficult with the open end mortgage, which is intended to serve as a vehicle for fiancing the utility for a long period of years, than is presented in designing covenants of this character for a mortgage which will be closed at or shortly subsequent to the time of its creation and which therefore will constitute a lien upon the property for a limited period of time. The general introduction of the open end mortgage was hastened by the radical change in interest levels and the rates of interest demanded by investors, which was one of the consequences of the European war. The economic conditions brought about by the war also led to an alarming increase in public utility receiverships, particularly in the case of electric railways, which brought glaringly to the attention of bankers the failure of the earlier and general provisions of the public utility mortgage to insure in all cases a proper standard of maintenance. For these reasons an obvious attempt has been made in all open end mortgages to provide a greater measure of assurance that the property will be well maintained. The nature of the provisions which have been inserted for this purpose show a wide dissimilarity. Time and experience will demonstrate which of these provisions will prove most efficacious.

It is manifestly impossible to catalog all of the provisions which have been inserted in open end public utility mortgages. In order to present the various plans most generally employed an examination has been made of a substantial number of representative mortgages constituting liens upon gas, electric light, 
urban and interurban railway properties. The maintenance provisions of these mortgages are classified for convenience under the following headings: "General," "Specific" and "Miscellaneous." A typical provision of each type is cited in the footnote. ${ }^{14}$

A somewhat more detailed analysis of a maintenance provision which is typical of those found in the so-called "General" and "Specific" groups will be helpful in determining the extent of the obligations assumed by the company.

\section{Analysis of a Typical "General Type" of Maintenance Provision}

As a rule the so-called general type of maintenance provision has included within it the company's covenant to: ${ }^{15}$

(I) Conduct its business in an efficient manner.

(2) Keep all property, equipment, etc., in thorough repair and in a state of high operating efficiency, corresponding to the progress of the industry.

(3) Safeguard its rights and franchises.

Bearing in mind what has previously been stated would a maintenance provision containing the above characteristics be satisfactory?

"General-"The company agrees to keep poles, wire, machinery, etc., in good condition and working order, and to keep up the renewals so as not to depreciate the value of the bonds. If the company fails to do this the Trustee may advance funds for this purpose and receive interest at $6 \%$ per annum." Lexington Utilities Co.

Specific-"Company agrees to set aside from gross operating revenues during each month for maintenance and replacement of properties an amount not less than 10\% of the gross operating revenues for such month. Any portion of this $10 \%$ not actually expended for current maintenance is to be segregated in a special reserve account which is to be used for maintenance expenditures in future years in excess of the 10\% requirement for the current year. If for any year expenditures exceed $10 \%$ of the gross operating revenues during said year, any excess may be credited upon the $10 \%$ of subsequent years. From time to time after January I, 1924, percentage of gross operating revenues may be redetermined."-Comnecticut L. \& P. Co.

Miscellaneous-"Shall expend or set aside annually from January I, I92r, 13\% of the gross operating revenue (not including outside earnings). If the company has not expended this amount any particular year, the deficiency shall be cumulative and shall be deducted from amount of additional property for which bonds may be issued. If the company has expended in excess to this stated amount, it shall be credited to it. . . May revise maintenance reserve triennially."-Puget Sound P. \& L. Co.

${ }^{23}$ The indenture analyzed is that of the Southern Cal. Edison Co. to Harris Trust \& Savings Bank-Los Angeles Trust \& Savings Bank, Trustee. 

tures?

First, does it provide for elasticity in maintenance expendi-

. It is elastic, as it does not stipulate that the company set aside a fixed amount. The company covenants to spend no more or less than is necessary to keep its entire property and equipment in a state of high operating efficiency, consequently it can expend a varying amount each year, dependent upon the condition of such property and equipment.

Second, does it adequately secure the bondholders?

Not necessarily. The determination of the amount required is to be made each year by the company. If the amount which the company sets aside is insufficient there is no provision in the mortgage by which this insufficiency shall be called to the attention of the trustee. The fees paid to corporate trustees for the administration of such trusts are not sufficient to enable the trustee to undertake an annual detailed examination of the property and it is not customary for the average corporate trustee to make any such annual examination. The experience of the past has demonstrated that a property may fall into disrepair, with a resultant large amount of deferred maintenance, without the situation becoming apparent to the trustee and without any steps being taken by the trustee to endeavor to remedy the situation. There are, practically speaking, no instances of record where corporate trustees have endeavored by legal action to compel utilities to increase the amount expended and/or set aside for maintenance and depreciation. The difficulties which would be encountered in an action of this character are substantial. The question of what should be set aside for maintenance in the absence of some specific provision is largely a matter of judgment. Who is to determine the amount to be expended by the company in maintaining its property in a state of high operating efficiency? Who is to determine the progress of industry? According to the provision, the company itself determines both the amount to be spent, and the progress of the industry. It would not be just, nor would it be accurate to assume, that the company, under such a provision, would deliberately allow its plant to deteriorate with- 
out taking proper measures to overcome this depreciation. But it is proper to assume that a company, like an individual, is always somewhat prejudiced in its own favor; and consequently, unintentionally, might not expend the amount necessary to maintain properly its equipment, or to keep its plant in a state of high operating efficiency, corresponding to the progress of the industry. Or again, the company might, with the best of intentions, misinterpret the present state of "the progress of the industry." In the past, most utilities when they were the sole judge of the amount which should be expended for maintenance spent extensively for that purpose when their incomes were relatively large, but neglected maintenance when their earnings were meager.

A trust company acting as trustee would have to rely upon the judgment of some engineering expert which it might retain. If, in an unusual instance, such an examination were made and the engineers retained by the trustee reported that the amount being expended and/or set aside was insufficient, the remedies open to the trustee to enforce the general covenant would be to endeavor by negotiation to get the company to increase the amount expended or set aside for these purposes and if it failed in this endeavor the only procedure prescribed in the mortgage in such an event would be for the trustee to declare a default to exist under the mortgage and to proceed to exercise the remedies therein provided in the event of default. This is a most serious step; from which a trustee would shrink except under circumstances where there could be no doubt of the wisdom of declaring a default. As a matter of fact, the average corporate trustee would be unwilling to assume the obligations and responsibilities involved in declaring such a default. A third course of action would be to endeavor to enforce the covenant by a suit against the company. There are practically no instances of record, however, where this step has been taken. As a practical matter, therefore, it follows that the weakness of the socalled "General Type" of maintenance covenants is that it places the responsibility for adequately maintaining the property upon the company and this is manifestly undesirable from the standpoint of the bondholder, and in the end is undesirable from the 
standpoint of the company's stockholders. The defects in the general type of the maintenance provision are: (I) The lack of a sufficient guarantee to the bondholder of adequate protection of the integrity of the physical property securing the bond; (2) the placing of an undue amount of responsibility upon the corporation.

\section{Analysis of the So-Called "Specific Type" of Maintenance Provision}

The distinguishing characteristic of the so-called specific type of maintenance provision ${ }^{16}$ is that the mortgage endeavors to set up a formula by which the amount which the corporation should expend and/or set aside for maintenance and renewals can be predetermined and the trustee enabled annually to ascertain whether the corporation is expending and/or setting aside the requisite amount. It is customary to include, in addition to the specific requirements above mentioned, a general covenant to maintain the property in good repair and condition. The customary covenants of the so-called specific type may be summarized as follows:

During the life of the present indenture the company agrees

(I) To keep all property in proper repair, so as to make its equipment efficient.

(2) To make, if necessary, renewals and replacements.

(3) To preserve diligently all rights, franchises and privileges granted to it.

(4) Starting with the calendar year I92I, and continuously thereafter, to expend or set aside, out of gross earnings for such year, for the Maintenance and Depreciation Fund, a sum equal to $12 \mathrm{I} / 2$ per cent. of said gross earnings. ${ }^{17}$

The indenture analyzed is that of the Kansas City P. \& L. Co. to Continental \& Commercial Trust \& Savings Bank.

${ }^{17}$ Some of the so-called specific type of provisions provided for the payment to the trustee of a sum equal to a percentage of the aggregate principal amount of all bonds secured by the mortgage, and the underlying outstanding mortgages constituting prior liens. Otherwise the provisions were similar to those 
(5) All expenditures, coming under I and 2, as well as any others that could be properly charged to maintenance and depreciation of property, shall be credited to the company in the calculation of the above fund.

(6) If the company fails to spend the total sum of this fund (mentioned in No. 4), it has the right to utilize the remainder of the fund for defraying the cost of permanent improvements, additions or betterments ${ }^{18}$ made during the past calendar year plus the first three months of the succeeding calendar year.

(7) If any balance remains, after payments made under No. 5 and No. 6 , it shall be paid by the company to the corporate trustee, who may apply it (at the option of the company), to the purchase of bonds at a price not exceeding their redemption price.

(8) These bonds shall be held uncancelled as part of the Maintenance and Depreciation Fund, and they may be sold by the Company, ${ }^{10}$ the proceeds to remain in the fund.

(9) The fund may be utilized by the company for maintenance, renewals, replacements, permanent improvements, ${ }^{20}$ additions or betterments.

(IO) The company may apply, at any time, for the certification and delivery of bonds ${ }^{21}$ on account of expenditures made out of this fund for permanent improvements, additions or betterments, for an amount not to exceed 80 per cent. of the cash cost or then fair market value thereof (whichever is lower).

provisions setting aside the percentage of gross earnings. For a complete provision in which the company covenants to set aside for maintenance a percentage of the principal amount of the outstanding bonds, reference is made to the provision in the mortgage of the "Pennsylvania Power and Light Company to Guaranty Trust Company of New York."

${ }^{28}$ These permanent improvements, etc., must not have been made the basis for (a) issuance of other bonds, (b) withdrawal of money from corporate trustee, (c) a credit as substituted property, (d) a previous credit to any other fund.

${ }^{10}$ With the approval of the corporate trustee.

${ }^{20}$ Supra note 18.

${ }^{21}$ Provided the conditions of Art. I, $\$ \S 8$ and Ix, are complied with; which sections relate to general conditions under which the company can issue additional bonds. 
(II) There must be deposited with the trustee as part of the Maintenance and Depreciation Fund, cash in amount equal to, at least, I25 per cent. of the principal amount of the bonds delivered under No. ro.

(12) This cash may be withdrawn by the company from time to time for maintenance, renewals or replacements of the company's property.

Is adequate protection afforded by maintenance covenants of the character above outlined? As has been remarked heretofore, a conclusive answer to this question can be afforded only by experience, gained by the passage of time. It is possible, however, by a careful study of past history to throw some light upon the adequacy of these provisions, and such an analysis is attempted in later sections of this study.

Before passing to a consideration of other methods of insuring adequate maintenance than those discussed in this chapter, it may be helpful to point out the probable practical effect of covenants of the types above described.

It should be noted at the outset that practically all covenants of the so-called specific type contain a specific provision to the effect that the enumeration of particular amounts which shall be expended or set aside for maintenance and depreciation shall rot in any way limit or affect the general obligation of the company to maintain adequately its property in good repair, working order and condition. It is obvious, however, that if main reliance must be placed upon the general covenant to keep the property in thorough repair and condition, because the specific amounts which the company is obliged to set up may for any reason be inadequate in the future, the value of the so-called specific covenants is highly problematical and we are back again to the status which prevailed prior to the introduction of the so-called specific type of maintenance covenants.

If the so-called specific type of covenants represents any real advantage or additional safeguard to the investor, it must be because the specific requirements are an assurance that the amount specified to be set aside and/or expended will at all times be adequate for the purposes intended. If the amounts specified prove 
to be inadequate, the existence of such specific covenants would, in practice, constitute no advantage to the investor and might conceivably work to his disadvantage because in any suit which might be instituted by the Trustee to compel the company to set aside larger amounts than those specifically set aside in the mortgage, a company could well plead that the amounts which should be set aside or expended had been specifically agreed upon at the time the mortgage was created and were presumably and prima facie adequate.

There is another angle to the problem which should be called to the reader's attention. Theoretically, at least, it is to the selfish interest of the bondholder to compel the utility to set aside more rather than less than is required for the purpose of maintenance and renewals, thereby insuring that the sums collected from rate payers and reinvested in the property or held in trust for this purpose shall at all times be equal to or in excess of the amounts actually required. In this connection, it must be remembered that covenants between bondholders, the trustee and a public utility company are not binding upon the public nor are they free from the control of the state commissions. A covenant requiring a company to expend or set aside a sum which was considerably in excess of the requirements of the property could, in effect, be negatived by action of the public service commission which, as has been remarked, is invested with authority to review the amount which the utility is entitled to collect to cover its operating expenses and a fair return upon the value of its property. Since expenditures for maintenance and renewals constitute a substantial part of the operating expenses, it follows that the public service commissions of the country are given a large measure of control over the amounts which the utility is entitled to collect from the rate payers for this purpose. It is customary to find that public service commissions, when considering the propriety of rates, give careful attention to the amount reasonably required for operating expenses, including as a part thereof the cost of maintenance and renewals. It follows, therefore, that it is impossible for the bondholder or trustee seriously to expect or to require a utility to set aside out of earnings an exorbitant amount for maintenance and renewals. 
As a practical matter, therefore, the effect of the specific type of maintenance provision is to set a minimum requirement as to the amount which shall be expended or set aside for this purpose.

A small percentage of the so-called specific type covenants require the utility to set aside a certain percentage of the total funded debt of the property, then issued and outstanding. The difficulties surrounding this method can be illustrated by the following hypothetical illustration: Suppose, for example, a utility has an investment at the time a mortgage is created of $\$ 10,000,000$, one-half of which is represented by proceeds from the sale of bonds, and that the mortgage provides the utility shall set aside out of earnings five per cent. of the aggregate principal amount of bonds then outstanding for maintenance and depreciation. This would be substantially equivalent to two and one-half per cent. of the then property investment. Let us assume that the utility, for some reason such as the desire to conserve its ability to do bond financing and to further improve its credit, as well as the desire to increase the security of its public relations by enlarging the number of customer-owners of the stock of the company, should decide to do all of its financing for several years through the sale of stock and that this policy is pursued until the point is reached where the company has an investment of $\$ 15,000,000, \$ 5,000,000$ of which is represented by bonds and $\$ 10,000,000$ of which is represented by the proceeds from the issue of stock. Under the maintenance covenant contained in the mortgage it would follow that although the property investment had been increased fifty per cent., the amount which the utility was obliged to set up for maintenance and renewals would be no greater than formerly. This illustration is, of course, somewhat at variance with the ordinary practice of public utility financing in the past, but it illustrates the difficulties which are encountered in endeavoring to fix proper expenditures for maintenance and depreciation in the future by the use of a formula which requires a utility to set aside a certain percentage of its funded debt then issued and outstanding. 
The Examination of Miscellaneous Types of MainteNANCE Provisions

A number of interesting attempts have been made to formulate maintenance provisions, in open end public utility mortgages, which shall possess a greater measure of elasticity than is afforded by the so-called specific type maintenance provision. The number of mortgages of this character, however, constitute a small proportion of the total open end public utility mortgages which have thus far been created. Under this heading an attempt will be made to analyze certain more or less typical examples of maintenance provisions which have been framed with the intent of providing a measure of elasticity by the provision of same method through which the specific amounts to be expended or set aside for maintenance or renewals can be periodically determined, thereby making possible such adjustments as may be required from time to time.

An interesting illustration of this type of maintenance provision is contained in the open end mortgage given by the Puget Sound Power and Light Company to the Old Colony Trust Company, Trustee, in r92I. This mortgage provides in effect:

(I) That 13 per cent. of the gross operating revenue shall be set aside annually. (In that respect this covenant is similar to the provisions frequently contained in mortgages in the so-called specific group.)

(2) For the triennial revisions of the Maintenance Reserve, if a revision is desired by either the Trustee, the Company or by Io per cent. or more of the bondholders.

(3) A revision may be fixed by an agreement between the Company and certain specified investment bankers filed with the trustee.

(4) If the above fail to agree, the requisite revision, if any, is to be determined by a board of arbitration.

(5) The board of arbitration is to be composed of three members-one chosen by the company, the second by the trustee from nominees nominated by any ten per cent. (xo\%) of the bondholders, or if no such nomination is 
made within thirty days, the trustee has full freedom of choice of the second member. The third member of the board is to be chosen within ten days after the said thirty days, by the first two members of the board, or in case of failure to do so within the ten-day period, the third member may be appointed by a judge of the United States Circuit Court of Appeals or by any judge agreed upon by the two arbitrators.

(6) A decision of a majority of the board of arbitration is to be conclusive; the expense of the arbitration is to be assumed by the company.

This differs from the usual type of provision in that it permits under certain circumstances a triennial revision of the maintenance, repair and replacement reserve.

A somewhat different type of covenant providing for a measure of flexibility in the annual appropriations for maintenance and replacements is illustrated by the provisions of the mortgage given by the Toledo Edison Company to the Bankers Trust Company in r92I. This mortgage provided that initially twelve per cent. of the gross operating revenues of the electric properties; ten per cent. of the gross operating revenues of the gas properties; and twenty-five per cent. of the gross operating revenues of the heating properties shall be expended or set aside for maintenance and renewals. The following provisions are made for the adjustment of these percentages:

(I) The percentages of gross operating revenue which were to be expended for maintaining the property may be adjusted at five-year intervals by agreement between the mortgagor and the Trustee.

(2) If the Company and the Trustee are unable to agree upon the revisions, if any, which are required, a board of arbitration composed of three members shall be selected to adjust the percentages.

(3) One member of the Board of Arbitration shall be named by the mortgagor, another member by the Trustee; the third member shall be chosen by those two members. 
(4) If the two members are unable to agree upon a third arbitrator, the senior Judge of the United States District Court for the district within which Toledo is located shall have power to appoint the third arbitrator.

(5) The mortgagor or the Trustee, upon the written request of the holders of Io per cent. (IO\%) of the principal amount of outstanding bonds, has power to initiate the readjustment of the percentages in the fifth year of the fiveyear period.

As contrasted with the covenants above cited, providing in effect for the periodical reconsideration of the adequacy of the percentages originally fixed in the mortgage or such adjustments therefor as have been made from time to time, another plan sometimes employed is to allow such revisions to be made not at the end of a three-year or a five-year interval but from time to time when in the opinion of a certain percentage of the bondholders it is deemed necessary or advisable to make inquiry with respect to the adequacy of the then prevailing appropriation. The mortgage given by the Savannah Electric and Power Company to the Commonwealth Trust Company, trustee, in I92I for example, provides that:

(I) Upon the request of the holders of at least ten per cent. of the bonds then outstanding, the trustee shall appoint a competent engineer or other person to examine the property with a view of ascertaining whether it had been adequately maintained, and if not to determine the sum represented by the undermaintenance.

(2) If insufficient maintenance is shown, by such examination, the trustee, upon the request of the holders of 5 per cent. in interest of the bonds outstanding, may apply the remedies provided in case of default.

This provision is exceedingly drastic and would be vigorously objected to by the average public utility company. It places in the hands of the civil engineer the power to declare a default under mortgage which, among other things, would compel the 
company to pay off the entire amount of bonds then issued and outstanding thereunder. It is doubtful whether it is wise to make it possible to take such sweeping action on the judgment of a single individual. Moreover, the attempt of the trustee to declare a default under such circumstances would doubtless be stubbornly resisted by the company, which would appeal to the courts for protection. The courts have been most cautious in declaring defaults and have shown extreme reluctance to declare such defaults unless the existence of a default is without question.

All of the covenants heretofore discussed in this section allow for periodical readjustments of the amounts to be expended or set aside for maintenance and renewals, and in so doing give recognition to the fact that changes in the cost of materials and the wages of labor and other factors heretofore reviewed at some length vitally affect the amounts which should be expended or set aside for these purposes. The comparative newness of these provisions leaves us without evidence as to how they will operate in practice. It is obvious, however, that the efficacy of such provisions will depend primarily upon the alertness of the trustee or on the percentage of bondholders, assuming that the company may not of its own volition adequately maintain its property.

In practically every instance it is optional with the trustee to conduct a periodical investigation of the adequacy of the provisions for maintenance and renewals. There is no obligation upon the trustee to take such action and the sweeping provisions of the mortgages limiting the liability of the trustee for acts of commission or omission would relieve the trustee of any responsibility if it fails to cause periodic examinations to be made of the adequacy of such expenditures. Under such circumstances, it is probable that many corporate trustees will not require frequent periodic examinations of the adequacy of the provisions for maintenance and renewals, especially if there has been no radical and revolutionary change in economic conditions which would naturally prompt such inquiries. The provisions of such covenants as are here under discussion are somewhat similar to the provisions commonly found in car trust indentures, giving to the trustee the power to examine the condition of rolling stock secured 
by such car trusts. It is a matter of common knowledge that trustees very infrequently take any steps to secure an independent opinion by a competent person with reference to the condition of the equipment secured by car trust obligations.

The practical value of the inclusion of covenants allowing a specified percentage of bondholders to institute action and thereby to require an examination of the sufficiency of maintenance and renewal expenditures is dependent, in most instancs, upon the alertness and sense of responsibility of the investment banking concerns which have marketed the bonds. The difficulty of getting a group of bondholders to cooperate with one another, even when there is a self-evident need for the protection of their savings, is a matter of common wonder. In the absence of any specific evidence that the property of the utility has been undermaintained, it would probably be difficult to get the bondholders of the company-particularly the average individual owner of such bonds-to join in a movement to compel an examination of the adequacy of the company's policy, assuming that the investment banker which has sold the bonds is not active in the campaign to secure such an examination.

A number of investment banking firms make it a practice to keep in close touch with the policies of the companies whose securities have been sold to their clients. Some of the leading dealers in public utility securities have in their employ experienced men who at more or less frequent intervals go over the properties which are regularly financed by the bankers for the purpose of observing the condition of the property and more or less regularly review the reports of the company for the purpose of determining the amounts which have been expended for maintenance and renewals as well as other matters. In such instances the banking firm would be able to make effective use of covenants of the type here under consideration; and though they would naturally hesitate to disturb the minds of their customers concerning the security of the bonds, they would nevertheless be able, in most cases, promptly to enlist the cooperation of the holders of the required percentage of bonds for the purpose of compelling the trustee to take the steps prescribed in the mortgage for deter- 
mining the adequacy of the maintenance and renewal program of the company.

On the other hand, a large proportion of investment banking firms have connected with them no special talent competent to determine questions of this character and do not make a practice of periodically examining the properties represented by the securities sold to their customers. The situation as it relates to banking firms of this group is well described in the following reply of a banker to a question propounded by the author:

"It is my understanding that bankers do not seriously undertake a study of the maintenance problems of the utility company about to issue bonds. They simply copy the provisions relating to maintenance and depreciation from some other indenture. In fact, I think that they could not go extensively into maintenance and depreciation if they wanted to. Further, if there is any problem about the corporation's living up to the provisions of the indenture, the trustee writes to the corporation and may or may not receive an answer."

It is probable that the so-called elastic type of covenant will not in all cases prevent insufficient maintenance or promptly call instances of insufficient maintenance to the attention of the trustee and the holders of the bonds. The old situation where the deferred maintenance comes to light after the company has allowed the property to deteriorate to a great extent and has, in many instances, defaulted on the interest on its bonds, will not be entirely eliminated by these covenants unless the trustee and the investment banker take steps to compel a periodical examination of the sufficiency of the expenditures for maintenance and replacements.

The Study of the Maintenance Experiences of a Number oF UंTILITIES

An attempt will be made to throw some light upon the feasibility of predetermining the amounts annually required for maintenance and renewals by the process of requiring a certain percentage of gross earnings or operating revenues to be set aside or expended for such purposes. The statistical analysis of the 
correlation of operating revenues on the one hand and the maintenance expenditures and appropriations for renewal reserves (sometimes called depreciation reserves) on the other, made by the author, covers a period of a decade in most cases, in other words, the years r9Io to I92I inclusive. It is true that this decade was most unisual. The revolution of operating costs resulting from the European War is not likely to be duplicated in magnitude in any succeeding decade in the life of the present generation, but there is no assurance that substantial variations in cost levels will not occur in the future and there is much evidence to point to the conclusion that cost levels will not remain stationary in the next few years. In view of the fact that the open end mortgage is intended as a permanent vehicle for financing public utility enterprises and therefore covers a long period of years, the mortgage should make provision to cover substantial changes in price levels and other important factors heretofore enumerated at some length which are almost certain to occur during the life of the lien.

An unusually interesting commentary upon the feasibility of prescribing that a certain percentage of gross revenues shall be set up for maintenance and renewals is furnished by the experience of the Third Avenue System and the New York Railways System operating most of the railway surface lines in New York City. In February, I9I2, the Public. Service Commission for the First District of New York, after prolonged study and valuations of the properties in question, involving a careful investigation of the then condition of the property, ordered the Third Avenue System and the New York Railways System to appropriate annually 20 per cent. of their operating revenues for the purpose of maintaining their respective physical properties. ${ }^{22}$ This percentage was adjudged by the Commission to be a liberal allowance and adequate to meet the maintenance requirements of the properties and to keep the physical property of the two corporations in a state of high operating efficiency, or in other words

${ }^{2} 3$ N. Y. Ist Dist. P. S. C. R. 52-59, II3-133 (I912). 
fully maintained. So far as the published report of the commission is concerned, the percentages prescribed in the orders of I92I have never been changed.

An examination of the actual correlation of operating revenues to the amounts annually expended by the two systems for maintenance in the years I9I4 to I92I, inclusive discloses that the Third Avenue System expended amounts varying from I5.65 per cent. in I916 to 21.73 per cent. in I92I, while the New York Railways System expended amounts varying from 20 per cent. to 34.40 per cent. during a like period.

The actual percentages expended clearly indicate that the Commission had misjudged the future maintenance requirements, and this assumption, it appears, is particularly true in the case of the New York Railways System. This conclusion is confirmed by the results of an examination undertaken by the Transit Commission of New York. The Transit Commission conducted an extensive investigation as of June 30 , I9zI to determine the present physical condition of these properties and the amount of deferred maintenance then existing. This examination disclosed the fact that the properties had been undermaintained during the period ending June 30 , I92 $\mathrm{x}$, notwithstanding the fact that they had in some instances expended more than the prescribed percentage. ${ }^{23}$ The extent of the undermaintenance as disclosed in the Commission's report indicated that the following expenditures, as of June 30 , I92I, would be necessary to place the physical properties in first class operating condition. ${ }^{24}$

Third Avenue System

New York Railways System
$\$ 4,377,406$

$\$ 15,176,926$

The fact that the New York Railways System found it necessary to expend, during the eight years from I9I4 to I92I, inclusive, annual percentages of its operating revenue for main-

\footnotetext{
${ }^{23} \mathrm{New}$ York Railways System-years I9I9, I920, I921. Third Avenue System-years 1920, I92I.

24 The Report on Valution as of June 30, I921, of the Physical Property of Rapid Transit and Street Surface Railroads in the City of New York-February 15, 1922; which was compiled by the Bureau of Valuation of the Transit Commission, State of New York.
} 
tenance of way and structures and maintenance of equipment which in some years were substantially in excess of the twenty per cent. of operating revenues adjudged by the commission in I9I4 to be adequate for this purpose, and the fact that the property in 1922 required an expenditure of some $\$ 15,000,000$ to put it in first class operating condition, shows clearly the difficulties confronting those who endeavor to predetermine the appropriation of operating revenues which must be expended in succeeding years for such purposes. Of course, the weakness of such a method of predetermining the amounts which should be expended for maintenance is most clearly demonstrated in the case of the New York Surface Lines by the fact that the franchise obligation to charge a five-cent fare, from which the companies were not released, prevented an adjustment of rates to accord with the profound changes which had occurred in the cost of operation. Revenues were fixed not with reference to what was reasonably required to defray the cost of service, including a fair return, but represented the amounts which could be earned at an arbitrary fare fixed under pre-war conditions while operating expenses, including the cost of maintenance, soared with the general advance in prices resulting from the war.

In the case of the Cleveland Railways Company, ${ }^{25}$ admittedly one of the best managed street railway companies in the world, the criterion was the "car-mile" and the average maintenance expenditure ordered was five cents per car-mile. The company, in order to maintain the highest operating efficiency, found itself required to expend from 7 cents to 14.35 cents per car-mile in the years I916-r924. The five-cent standard was adequate only in the years I9II-I9I5, when conditions approximated those that existed at the time the order was made.

A study of the maintenance experience of the electric light and power companies ${ }^{26}$ and of the gas companies ${ }^{27}$ discloses the

\footnotetext{
${ }^{25}$ See J. H. Davis, American Electric RaIlways Accountant AssociaTION, October 12, 1920 .

${ }^{\star S}$ See Reports of the Massachusetts Commission (1914-rgar) and the New York Commission (1910-1922).

${ }^{27}$ See Reports of the Massachusetts Commission (1910-1921) and the New York Commission (I910-1922).
} 
same situation, as does an examination of the records of the electric interurban street railways. ${ }^{28}$

The conclusions reached from these maintenance experiences are that the gas, electric light and power, and electric interurban utilities have in the past annually expended for maintenance amounts which varied considerably from previous annual expenditures made for the same purpose, and that no evidence exists which will lead us to believe that the amounts expended for maintenance in the future or the percentages thereof to operating revenues will not fluctuate to a substantial degree. A like conclusion is reached in the case of the urban street railways. Therefore, taking into consideration the past experiences of the utilities $^{29}$ together with the fact that the elements or factors not predictable are all still in more or less active operation, the difficulty of an attempt to estimate the necessary amount to be expended for maintenance some years hence by prescribing a percentage of operating revenue, is apparent. In the light of past experience, the conclusion seems inevitable that it is impossible to estimate, with any degree of accuracy, the amount which must be expended for maintenance in the comparatively distant future. It might be stated that the practice of prescribing that a certain percentage of operating revenues shall be set aside for depreciation has been the subject of review by a number of state commissions in connection with rate proceedings or valuation matters then pending. The Wisconsin Railroad Commission In re Wisconsin Traction, Light, Heat and Power Company ${ }^{30}$ made the following comment with respect to this matter:

"The Wisconsin Traction, Light, Heat and Power Company, instead of reserving each year a percentage of the depreciable plant value based upon a composite life study, ignores such value entirely, and sets aside a percentage of the gross revenues. This is a very convenient method used by a smaller number of utilities. It has the advantage of regulating the amount provided for depreciation in accordance

${ }^{23}$ See Reports of the Illinois Commission (Igro-IgI7) and the New York and Ohio Commissions (1910-1922).

20 Transit, electric interurban, electric light and power, gas utilities.

${ }^{20}$ P. U. R. IgIgB 224, 234 (Wis.). 
with the gross income but a reserve so provided may have no proper relation to the deterioration actually taking place in the property, because it is fixed entirely independently of the invested values. The progress of a plant in earning power is almost always distinct from its progress in depreciation or appreciation."

The Illinois Public Utilities Commission In re Illinois Northern Utilities Company ${ }^{31}$ has taken the same position:

"To base allowance for depreciation upon a percentage of the gross revenue of a street railway company which fluctuates with changed transportation conditions and sales is improper."

Conclusions With Reference to Effectiveness of Matntenance Provisions Most Commonly Used in Open End Mortgages and Some Suggestions for Improventents THEREIN

At various points in this study, comments have been made on the lessons which which might be drawn from the statistical studies which have been made to determine the correlation of operating revenues and expenditures for maintenance and depreciation, and with reference to a number of other plans commonly employed to prescribe in advance the amounts which a utility shall expend or set aside to insure a high state of repair and timely renewals and replacements. It may be helpful, however, to review at this point in a more general fashion the lessons which are apparently indicated by the investigation which has been made by the author, and to endeavor to appraise the probable adequacy of the more commonly employed methods of insuring a proper standard of maintenance.

At the outset it should be emphasized that the growing appreciation by public utility operators and the owners of the stock of such corporations of the disastrous consequences which follow a niggardly policy with reference to maintenance and renewals constantly lessens the potential danger of inadequate provision for

${ }^{21}$ P. U. R. I920E 908 (III.). 
this purpose. Experience has shown that where a utility is able to enjoy good earnings under rates which the public is willing to pay, the tendency to under-maintenance is seldom, if ever, present. Under-maintenance as a rule develops where, because of changed economic conditions lessening the demand for the company's service, or requiring a reduction in rates to meet competition, or for other like reasons, the utility finds itself in straightened circumstances and faces the alternative of curtailing dividends or perhaps passing the interest on its bonds in order to insure adequate provision for maintenance and depreciation; or, on the other hand, of curfailing maintenance and setting up little or nothing for depreciation, distributing the amount thus saved to security holders with the hope that conditions may improve and the company later find itself in a position to catch up on the deferred maintenance, whatever it then may be. The regulation of security issues by public service commissions, decreasing the likelihood of over-capitalization, has eliminated one of the most fruitful causes in the past for slighting maintenance and making insufficient provisions for depreciation in order to carry a top-heavy load of fixed charges.

It is much less likely that a company will slight current maintenance than that it will make insufficient provision for future replacements and renewals through adequate appropriations for depreciation reserves. The immediate need of replacements and repairs are obvious and are capable of more or less exact determination. The amount which will be required in the future to replace major units of property is a matter of estimate, depending primarily, in a large percentage of cases, upon the economic rather than the physical life of the property in question. It is very easy, therefore, to under-estimate the amount which would be required for replacements and renewals in the future and it is no doubt true that many companies are currently accruing too little for this purpose. There is no more reason to assume, however, that the judgment of the company's engineers with reference to what will be required to make such future replacements and renewals will be any less fallible than the judgment of the engineers representing the investment banking concern which is in 
reality the other party in interest in drawing the corporate mortgage containing specific provisions for making such accruals in the future.

The greatest difficulty inherent in drawing a provision which requires that a specific amount shall be set up by the utility for maintenance and depreciation in the future is that the problem concerns not only the physical situation now existing but contemplates a proper evaluation over a period of several generations of all of the attendant uncertainties, which are contained in an attempt to guess the relative progress of the art in the years to come; the life of the equipment which will replace that now in existence; the change in community habits and requirements, which governs the very important factor of inadequacy; and other factors which no man accurately can foresee or predetermine but which nevertheless are evaluated, or attempted to be evaluated, in the percentages which are contained in the maintenance covenants of the mortgage. It would almost be miraculous if amounts which were adequate today would be neither too much nor too little thirty or fifty years from today under an entirely different economic situation and with a property whose physical characteristics is then substantially dissimilar from the present property.

The only value of a covenant requiring the appropriation of specific amounts, or amounts determined by the application of a specific formula, is to insure that the sum thus arrived at will be adequate. If it is inadequate, the bondholder has no greater protection than he would possess with a general covenant requiring the company to keep the property in good order and repair and to make adequate provision for maintenance and depreciation. If it is excessive, the bondholder runs the danger that the public service commission will, in effect, strike it down by ordering the utility to set aside for depreciation a smaller sum than that specified in the mortgage, which would mean that the difference would have to be set up as a reserve out of the return going to the stockholders. If this should follow, and the amount be substantial, the corporation's credit would be adversely affected because the stockholder would receive a return less than that which he should otherwise en joy and such decreased return might adversely affect 
the company's credit which would in turn sympathetically depress the price of its bonds.

The long-time value of specific covenants of the characten commonly employed at present is therefore highly problematical, particularly where no provision is made in the mortgage for adjusting the percentages specified, to meet changed economic conditions, by allowing the corporation and the trustee to make modifications in the mortgage with the assent of a specified percentage of the holders of the bonds then issued and outstanding. In other words, it is probable that a large proportion of the so-called open end mortgages which have heretofore been issued will become an obsolete and inadequate method of financing these utilities because of the fact that with the passage of time the mortgage contains covenants which are inapplicable to the then existing conditions and which either fail to protect the bondholders, with the result that the utility would not be able to sell additional series of bonds to investment bankers upon favorable terms, or which will hamstring the utility by requiring it to meet onerous, exorbitant and unnecessary conditions. . It is only within the last few months that this more or less obvious danger has been recognized by investment bankers and corporation lawyers and an attempt made to keep the mortgage abreast of the times by allowing amendments to be made thereto under proper restrictions. It is just as foolish to assume that the corporate mortgage will be adequate to meet the situations which will prevail in the years to come as it would be to have assumed that the United States Constitution would for all time have been an adequate instrument of government without any provision for its amendment as changed conditions might require.

If the experience of the past is any guide as to what will be encountered in the future, it seems certain that maintenance covenants of the so-called specific type in open-end mortgages which do not contain any provision for elasticity or modification to meet changed conditions will, in the long run, prove of problematical value to the investor and may in some cases even work to his detriment. The only covenants of the so-called specific type which, beyond doubt, will be of lasting permanent protection to 
the investor are those which provide some machinery for the periodic readjustment of the amounts which the utility is required to set aside or expend for maintenance and depreciation. The difficulties which present themselves in providing a practicable method for making such periodic adjustments have heretofore been touched upon at some length.

The open-end mortgage is a very new vehicle of corporate financing. It is surprising that such rapid progress has been made in working out this form of mortgage. It is generally conceded that the bond investor is better protected, under this mortgage than under the old type of inelastic mortgage which it has generally superseded. The fact that it is a difficult problem to work out some practicable plan for insuring adequate maintenance and depreciation accruals is no excuse for failing valiantly to attempt to work out a practicable solution. The fact that the trustee is generally a financial institution whose officers are incapable of determining from their own experience or observation what is required from time to time for maintenance and depreciation; that the trustee must, therefore, rely upon expert advice from those qualified to express judgment as to what is required for this purpose; the difficulties of providing some machinery by which a periodic analysis of the adequacy of the appropriations can be made from time to time; the expense which is involved in such examinations and determinations and the objections which utility companies naturally offer to being required to defray the cost of such investigations; the question as to the attitude which the courts will assume toward the right of the trustee to force the utility to set up the amounts which may be found necessary by such expert examinations-are all matters of vital concern which cause corporation lawyers and investment bankers to proceed with great caution in radically departing from the accepted methods and standards currently in vogue.

For the purpose of stimulating further consideration of the problem, and of contributing if possible to the development of a more perfect form of maintenance covenant which will more 
adequately protect the investor but will not prove unnecessarily onerous to the utility, the following suggestions are offered for consideration:

(I) If it is granted that the so-called elastic type of maintenance covenant, providing for a periodic readjustment of the amounts which shall be set up for this purpose, is superior to the so-called specific type fixing definite amounts which shall be set up in each year thereafter without provision for any periodic adjustment, it follows that the most desirable type of covenant should be one which provides for periodic readjustments of the amounts which the company is required to set aside for these purposes.

(2) The danger in the so-called elastic type covenant is that the trustee will take no.steps to cause a re-examination of the adequacy of the current accruals for maintenance and depreciation and to insure that the readjustments will be made, until a large amount of deferred maintenance has accrued. In order to overcome this danger it is suggested that it is advisable to require the trustee to cause a periodic examination to be made by some one qualified to express an opinion as to the adequacy of the appropriation for maintenance and depreciation under the then existing situation.

(3) The utility and the rate payer may properly object to the unnecessary expense which would be entailed in a too frequent examination for the purpose of determining these questions. It is obvious that the company must defray the cost of these examinations, and since the only source of revenue which the company enjoys is the revenues secured from the rate payer, it follows that the public has an interest in this matter and should not be required to pay the cost of an unnecessarily elaborate or cumbersome procedure to protect the investor. 
(4) It is suggested that the desired end may be served by having the mortgage require the trustee to have an annual examination made of the property by some engineer or qualified person selected by the trustee, whose training and experience enables him to determine the then condition of the property and the adequacy of the current appropriations for maintenance and depreciation. The written report of the examiner should be open to the inspection of any bondholder.

(5) The mortgage should require the trustee, in the event that the examiner reports that the state of repair of the property has deteriorated or that in his judgment the current appropriations for maintenance and depreciation are either inadequate or probably inadequate, forthwith to take steps to secure a determination of the adequacy of the current appropriations by a Board of Arbitration.

(6) The mortgage should provide for the method of appointment of such a Board. The current practice of requiring a board of three members, one selected by the company, one by the trustee, either on its own initiative or from a list submitted by the holders of a required percentage of the bonds, with the third member to be chosen either by the first two mentioned members or by some disinterested outside agency, such as a judge of a United States Court, is probably adequate to secure an authoritative and disinterested judgment by a qualified jury as to what should be set aside for maintenance and depreciation. The mortgage should make it mandatory upon the trustee to cause the Board of Arbitration to be appointed and function if the annual examination discloses any doubt as to the sufficiency of the provision Ior maintenance and depreciation, and should make the findings of the Board binding upon both the company and the trustee and should provide machinery by which 
these findings may be enforced by the declaration of a default and/or by such other measures as may be appropriate under the specific conditions in each case.

(7) The expenses of the annual examination and of the Board of Arbitration should, of course, be borne by the company, and if unpaid, should constitute a lien upon the property.

The possible objections to such a plan-that it involves substantial expenditures on the part of the company and a degree of watchfulness and responsibility on the part of the trustee, which trust companies have heretofore not been required to assumeshould not be allowed to outweigh the necessity for making adequate provision for the protection of the investing public, and for the insurance of first-class service to the patrons of the utility, neither of which would be possible if the property were allowed to fall into disrepair or inadequate provision was made for keeping it abreast of the progress of the. art. It would, of course, be possible to impose much more drastic provisions than those abore suggested. It must be remembered, however, that the interests of the bondholder and of the company should be and are identical. From an economic point of view they are partners in an industry, and the greatest co-operation should exist between them in order to increase the earning capacity of the company, and thus make it easier for the company to pay the interest due to those who have advanced their capital savings. It is a fact that increased earnings are dependent to the greatest extent upon the adequate maintenance of plant and equipment, and there is every reason to suppose that the proposed plan of insuring adequate maintenance will tend to develop this spirit of co-operation between debtor and creditor.

University of Pennsylvania. 